Article

\title{
Drop Size Distribution Measurements in Outer Rainbands of Hurricane Dorian at the NASA Wallops Precipitation-Research Facility
}

\author{
Merhala Thurai ${ }^{1, * \mathbb{C}}$, Viswanathan N. Bringi ${ }^{1}$, David B. Wolff ${ }^{2}$, David A. Marks ${ }^{2}$ and \\ Charanjit S. Pabla ${ }^{2,3}$ \\ 1 Department of Electrical and Computer Engineering, Colorado State University, \\ Fort Collins, CO 80523, USA; bringi@engr.colostate.edu \\ 2 NASA GSFC Wallops Flight Facility, Wallops Island, VA 23337, USA; david.b.wolff@nasa.gov (D.B.W.); \\ david.a.marks@nasa.gov (D.A.M.); charanjit.s.pabla@nasa.gov (C.S.P.) \\ 3 Science Systems and Applications, Inc., Lanham, MD 20706, USA \\ * Correspondence: merhala@colostate.edu; Tel.: +1-970-491-7678
}

Received: 21 April 2020; Accepted: 29 May 2020; Published: 1 June 2020

\begin{abstract}
Hurricane rainbands are very efficient rain producers, but details on drop size distributions are still lacking. This study focuses on the rainbands of hurricane Dorian as they traversed the densely instrumented NASA precipitation-research facility at Wallops Island, VA, over a period of $8 \mathrm{~h}$. Drop size distribution (DSD) was measured using a high-resolution meteorological particle spectrometer (MPS) and 2D video disdrometer, both located inside a double-fence wind shield. The shape of the DSD was examined using double-moment normalization, and compared with similar shapes from semiarid and subtropical sites. Dorian rainbands had a superexponential shape at small normalized diameter values similar to those of the other sites. NASA's S-band polarimetric radar performed range height-indicator (RHI) scans over the disdrometer site, showing some remarkable signatures in the melting layer (bright-band reflectivity peaks of $55 \mathrm{dBZ}$, a dip in the copolar correlation to 0.85 indicative of $12-15 \mathrm{~mm}$ wet snow, and a staggering reflectivity gradient above the $0{ }^{\circ} \mathrm{C}$ level of $-10 \mathrm{~dB} / \mathrm{km}$, indicative of heavy aggregation). In the rain layer at heights $<2.5 \mathrm{~km}$, polarimetric signatures indicated drop break-up as the dominant process, but drops as large as $5 \mathrm{~mm}$ were detected during the intense bright-band period.
\end{abstract}

Keywords: drop size distribution; generalized gamma model; hurricane Dorian rainbands

\section{Introduction}

Hurricane Dorian was an intense tropical cyclone that first made landfall in the Caribbean on 27 August 2019 as a Category 5 hurricane. A few days later, it reached the United States near the Florida coast line. The storm then headed northward along the east coast of the continent while weakening in intensity and subsequently transitioning to a post-tropical cyclone. Dorian's path included the Delmarva Peninsula (almost as a Category 1 hurricane) with outer rainbands having traversed a well-instrumented validation site at the NASA Wallops Precipitation Research Facility (PRF) [1]. The PRF comprises a network of ground instruments including various types of disdrometers, rain gauges, anemometers, micro rain radars, and NASA's S-band polarimetric radar, referred to as NPOL, located $38 \mathrm{~km}$ away. The NPOL radar made regular observational scans over the ground instruments during the rainband period. In this paper, we examine disdrometer-based drop size distribution (DSD) measurements, rain gauge data, and NPOL radar observations, specifically the range height indicator (RHI) scans along the azimuth over the ground instruments made over a period of $8 \mathrm{~h}$. DSD data were analyzed in terms of the underlying shape of the distributions, 
and their characteristics are correlated with copolar reflectivity $\left(Z_{h}\right.$ or $\left.\mathrm{dBZ}\right)$ for horizontal polarization, and differential reflectivity $\left(\mathrm{Z}_{\mathrm{dr}}\right)$ between horizontal and vertical polarizations. Pluvio rain gauge data were used for providing rainfall rates to compare against the DSD-based rain rates.

Tropical cyclones are often characterized by a high concentration of small- and medium-sized drops. Several airborne measurements within the eyewall regions and rainbands were previously reported [2-5]. Apart from disdrometer measurements, dual-polarization observations have also been made for a number of hurricane events. A very recent study [6] examined DSD characteristics in the eyewall region of hurricane Harvey using dual-polarization radar observations from the United States (U.S.) weather radar (WSR-88D) network. Didlake and Kumjian [7] studied in detail polarimetric data in the eye wall, and inner and outer rainbands, and found significant differences in the vertical profiles of $Z_{h}, Z_{d r}$, the copolar correlation coefficient $\left(\rho_{\mathrm{hv}}\right)$, and the specific differential propagation phase $\left(K_{d p}\right)$, both below and above melting level, indicating different microphysical processes. Brown et al. [8] compared $Z_{h}, Z_{d r}$ variability with several microphysical schemes. They found that the measured $Z_{d r}$ (for a given $Z_{\mathrm{h}}$ ) was much smaller as compared to that of numerical models (i.e., drops were much smaller than those predicted by models). Wolff et al. [9] also examined WSR-88D radar observations during hurricane Harvey, but the main aim there was to assess the use of specific attenuation for estimating rainfall rates.

Modelling rain DSD has been conducted in numerous studies dating back to [10]. There, DSD was modelled in the form of exponential distribution whose slope parameter depends on rainfall intensity. Later, Ulbrich [11] adopted three-parameter gamma distribution to model the measured DSD at shorter time scales of a few minutes. Gamma distribution has been used almost exclusively in numerous studies to model DSD characteristics, with [12] being a more recent example. It has been the basis for retrieving the parameters of the model using polarimetric-radar measurements $([13,14]$ and references therein).

A number of methods involving scaling-normalization of the DSD $[15,16]$ and the unified approach of Lee et al. [17] termed as double-moment normalization allow for separating DSD in terms of two reference moments along with the generic shape represented by $h(x)$, where $x$ is the scaled diameter [18]. For DSD shapes that exhibit double curvature such as equilibrium-like shapes, the generalized-gamma (GG) model $[17,19]$ with two shape parameters $(\mu, c)$ is more flexible. In addition, power-law diameter functions such as mass or mass flux also follow the GG model [20].

In a recent article, Raupach and Berne [21] demonstrated that generic shape $h(x)$ is invariant in stratiform rain, i.e., greater than $85 \%$ of DSD variability was captured by the two reference moments (third and the sixth) in the double-moment normalization. Their data analysis also suggested that convective rain DSD possibly exhibits similar behavior. In this paper, we continue with the same double-moment normalization approach, and examine the suitability of the GG model to represent $h(x ; \mu, c)$ derived from the disdrometer measurements in the rainbands of hurricane Dorian.

The paper is structured as follows. In Section 2, we briefly describe the ground instruments used in this study and S-band NPOL radar observations. DSD examples and data analyses for the entire observation period are presented in Section 3. NPOL observations over the disdrometer site are given in Section 4 and correlated with the results from the DSD analyses in Section 5. This is followed by concluding remarks in Section 6.

\section{Instrumentation}

Figure 1a shows the composite radar image of hurricane Dorian from the U.S. weather radar network over and around the ground observation site. The site, marked with a " + " sign, is located in the coastal region of the Delmarva peninsula. At the time of this image (around 10:15 UTC on 6 September 2019), the outermost rainbands are clearly visible near the instrument site, whereas the eye of the storm was situated just south of the image frame. 

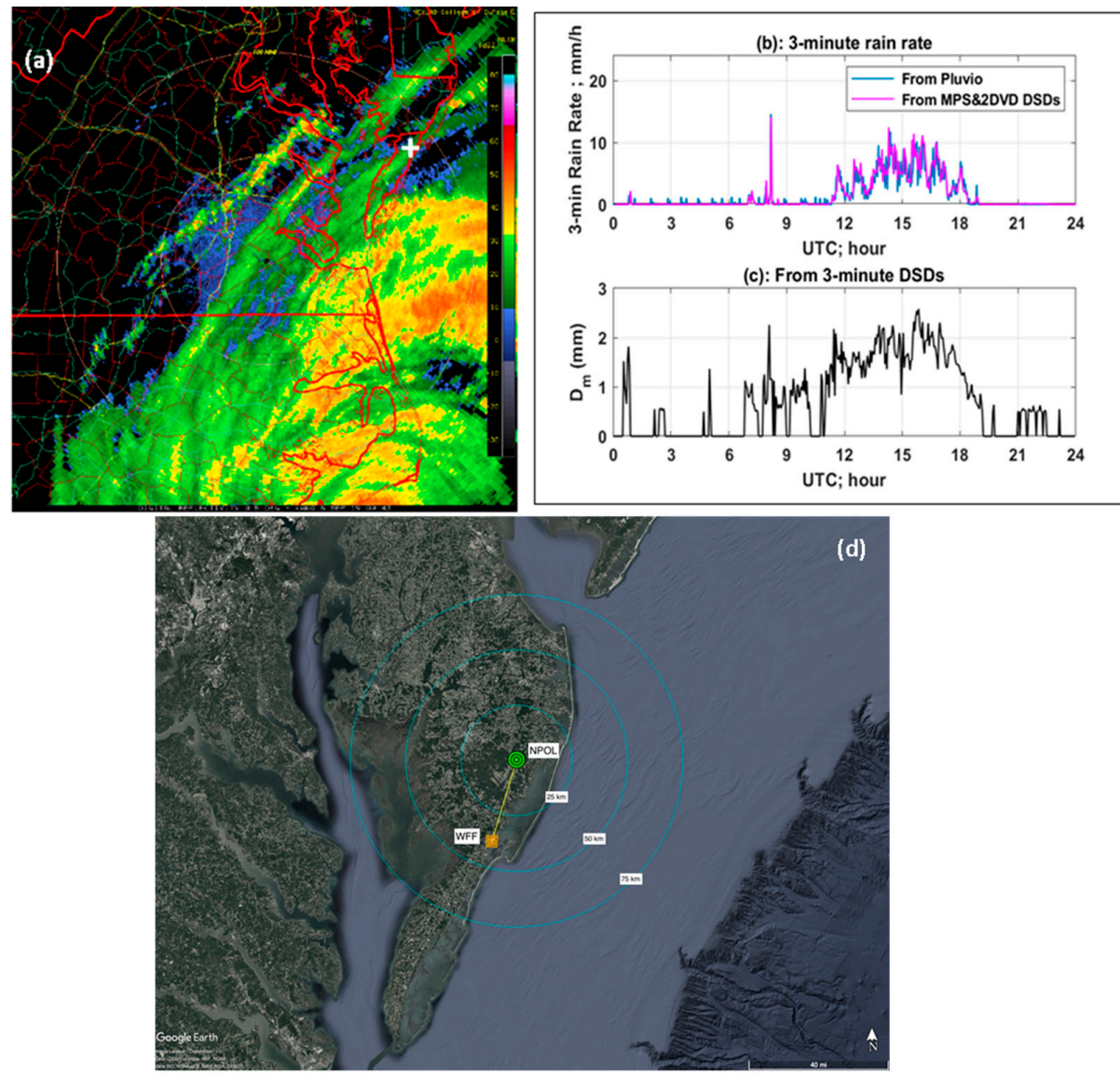

Figure 1. (a) Composite radar image of rainbands of Category 1 hurricane Dorian over Wallops ground instrumentation site (white cross) at beginning of storm on 6 September 2019; (b) 3 min rainfall rate from Pluvio gauge and from combined disdrometer drop size distribution (DSD); (c) mass-weighted mean diameter from 3 min combined DSDs; (d) NPOL radar and disdrometer location.

The instrument site is part of the ground validation activities in support of NASA's global precipitation measurement (GPM) mission [22]. A network of many ground instruments with multiparameter radar observations not only provide pertinent data for validating GPM-based products, but also enable studies on precipitation microphysics. The ground instruments include various types of disdrometers and rain gauges. Here, we utilized data obtained from two disdrometers, namely a meteorological particle spectrometer (MPS) [23-25] and a 2D video disdrometer (2DVD) [26,27], as well as a Pluvio rain gauge [28], all collocated at the same coastal region. The MPS was installed within a double wind fence (DFIR) [29] in order to reduce the effects of high winds on DSD measurements. This setup was similar to that of two other sites, one in Greeley, Colorado, and one in Huntsville, Alabama (see Figure 1 of [30]). While the MPS enabled relatively accurate measurements of drop concentration for drop diameters below $1.2 \mathrm{~mm}$, the 2DVD provided more accurate measurements for larger diameters $(>0.7 \mathrm{~mm})$. As with Greeley and Huntsville data analyses, we composited drop size distribution from each instrument (typically 3 min averaged) using the MPS for D $<D_{\text {th }}$ and the 2DVD for $\mathrm{D} \geq \mathrm{D}_{\text {th }}$, where $\mathrm{D}_{\text {th }}$ is a threshold diameter in the overlap range from 0.75 to $1 \mathrm{~mm}$ [31]. Due to high gusting winds, the data quality of the MPS concentrations for $\mathrm{D}<0.5 \mathrm{~mm}$ could not be firmly established; so, to be conservative, we used $0.5 \mathrm{~mm}$ as the lower limit for the MPS. Further $\mathrm{D}_{\text {th }}$ was selected as $1 \mathrm{~mm}$; thus, by combining data from two disdrometers, truncation at the small drop end was partially overcome. The composite DSD that resulted was considered to be a substantial improvement over using a single 2DVD alone. 
Rainfall rates derived from DSD spectra were compared with Pluvio-based rainfall rates, shown in Figure $1 \mathrm{~b}$ for the entire day. Both showed fluctuating rain rates (peak rates seemed to be spaced, on average, $45 \mathrm{~min}$ apart, so $3 \mathrm{~min}$ DSD could adequately resolve the features), as the (main) rainbands traversed the instrument site from 11:00 to 19:00 UTC. Figure 1c shows mass -weighted mean diameter $D_{m}$ derived from the composite DSDs (ratio of fourth to third moments). As seen, values of $D_{m}>2 \mathrm{~mm}$ occurred several times during the event, with a maximal value of $2.5 \mathrm{~mm}$ at around 15:45 UTC. Rain rates ( $3 \mathrm{~min}$ averaged), on the other hand, reached a maximum $(\sim 12 \mathrm{~mm} / \mathrm{h})$ earlier, at around 14:20 UTC.

The NPOL radar was used for continuous observations during the main part of the event. This radar is a unique and valuable resource for both NASA Earth sciences and external communities. The antenna system provides for better than $1^{\circ}$ beam width and electrical performance (side lobe and cross-polar patterns) consistent with the collection of research-quality polarimetric data. The radar signal processor was upgraded to the SIGMET/Vaisala RVP-900. The processor provided a robust means to collect and process raw I/Q (in-phase and quadrature-phase) and moment data in both conventional alternating (full covariance matrix) and simultaneous transmit/receive modes.

The locations of the NPOL radar and the instrument site at Wallops island are shown in Figure 1d. Blue circles represent a radar range of up to $75 \mathrm{~km}$ in steps of $25 \mathrm{~km}$. The disdrometer site is marked in orange (WFF).

During the Dorian event, the scan strategy comprised a sequence of (a) PPI (plan position indicator) volume scans with 12 different elevations ranging from 0.7 to $20^{\circ}$; (b) RHI scans with azimuths of 195, 197 , and $199^{\circ}$; and (c) vertical (birdbath) scans with two revolutions at $90^{\circ}$ for $\mathrm{Z}_{\mathrm{dr}}$ calibration. In this paper, we made use of RHI scans made along the $197^{\circ}$ azimuth along which the disdrometer site was located $(37 \mathrm{~km})$. The overall sequence of PPI, RHI, and birdbath scans was repeated every $7 \mathrm{~min} 15 \mathrm{~s}$.

\section{DSD Analysis}

\subsection{Double-Moment Normalization}

To analyze DSDs, we used the double-moment normalization approach of Lee et al. [17], given by:

$$
\mathrm{N}(\mathrm{D})=\mathrm{N}_{0}^{\prime} \mathrm{h}(\mathrm{x})
$$

where

$$
N_{0}^{\prime}=M_{i}^{\left(\frac{j+1)}{(j-i)}\right.} M_{j}^{\left(\frac{i+1)}{(i-j)}\right.}
$$

and

$$
\mathrm{x}=\frac{\mathrm{D}}{\mathrm{D}_{\mathrm{m}}^{\prime}} .
$$

D being the equivolume drop diameter, and $\mathrm{D}_{\mathrm{m}}^{\prime}$ given by:

$$
D_{m}^{\prime}=\left(\frac{M_{j}}{M_{i}}\right)^{\frac{1}{(j-i)}} .
$$

This is a generalization of Testud et al. [16], and Illingworth and Blackman [32]. To be consistent with our previous analyses of the Greeley (GXY) and Huntsville (HSV) datasets, we chose the third and fourth moments as the two reference moments by setting $i=3$ and $j=4$. Under these conditions, $D_{m}^{\prime}$ is equal to $D_{m}$ (henceforth used interchangeably) and $N_{W}=\left(4^{4} / 6\right) M_{3} /\left(D_{m}{ }^{4}\right)$, as in [16], where $M_{3}$ is the third moment.

Examples of $h(x)$ versus $x$ are shown in the four panels of Figure 2 that were derived from the 3 min DSDs during (a) 00:00-01:00, (b) 12:00 -13:00, (c) 14:00-15:00, and (d) 16:00-17:00 UTC. The last three panels correspond to the main rainbands, whereas the first panel corresponds to a small fragment of an isolated cell that became detached from the outer bands. All four showed similar shapes, 
although the first panel showed more scatter because of the limited number of DSD samples. Each plot had the composite, i.e., the most probable $\mathrm{h}(\mathrm{x})$ superimposed in red that was previously derived from the GXY and HSV datasets (inclusive of convective and stratiform rain [31]). The composite $h(x)$ corresponds to the GXY and HSV datasets with more than 40003 min DSDs from a variety of rain types, from semi-arid and subtropical climates, with each DSD being fitted to the generalized gamma model (see Section 3.2). The median values of the shape parameters were then used to determine the composite $\mathrm{h}(\mathrm{x})$.

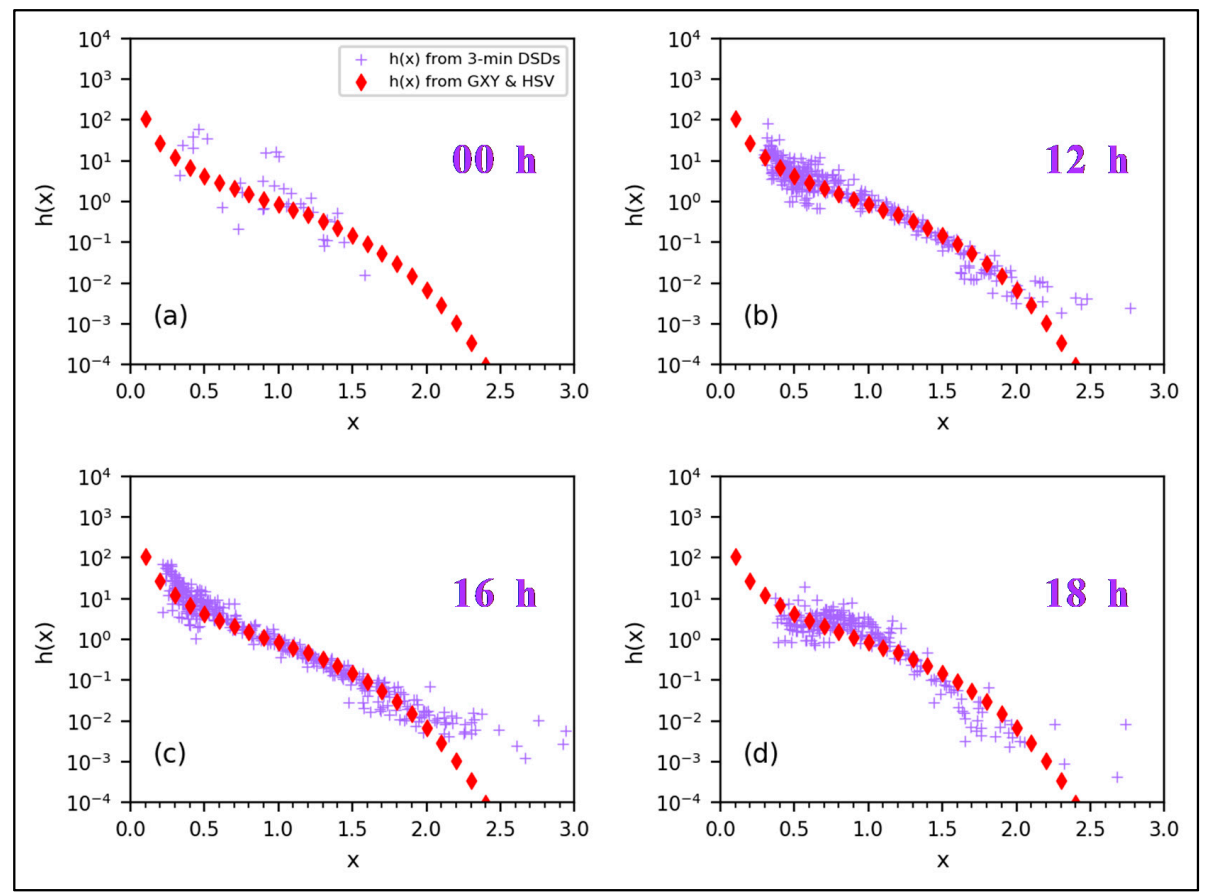

Figure 2. $h(x)$ versus $x$ derived from 3 min DSDs for (a) 00:00, (b) 12:00, (c) 16:00, and (d) 18:00 UTC, shown as purple crosses. Red diamonds represent most probable $\mathrm{h}(\mathrm{x})$ versus $\mathrm{x}$ from composite DSDs from the Greeley (GXY) and Huntsville (HSV) datasets with more than 40003 min DSDs from a variety of rain types [31].

Good agreement can be seen in Figure $2 b, c$ for $x=0.25$ to $x=2$. Beyond $x=2$, sampling errors may play a role, but consistent underestimation is seen. Even though the minimal D was set at $0.5 \mathrm{~mm}$ for MPS data acquired during Dorian rainbands, the corresponding $\mathrm{x}$ could go as low as 0.25 (when $\mathrm{D}_{\mathrm{m}}=2 \mathrm{~mm}$ ). Overall, for the main period of the rainbands (10:00-17:00 UTC), the $\mathrm{h}(\mathrm{x})$ for $0.25 \leq \mathrm{x} \leq 2$ appears to be fairly well-represented by the most probable $\mathrm{h}(\mathrm{x})$ shown by the red diamonds. Further ongoing improvements to the data quality of the MPS measurements during the rainbands might allow for reducing the minimal $\mathrm{D}$ to $<0.5 \mathrm{~mm}$, and it is entirely possible that the composite $\mathrm{h}(\mathrm{x})$ may require adjustment for rainbands associated with land-falling hurricanes [7,8]. The form of this adjustment could be related to the shape parameters $(\mu, c)$ of the generalized gamma model fit to $h(x)$ [33]. Figure $2 d$ corresponds to the end of the rainband passage over the Wallops site. Here, the shape of $h(x)$ showed some differences, particularly in the $x=0.5$ to 1 region, where more flattened variation was observed.

The double-moment normalized spectra from 06:00 to 20:00 UTC are all plotted in Figure 3a. There was considerable similarity with Figure 7a in [17], which also used $i=3$ and $j=4$. The composite $h(x)$ (from GXY and HSV, plotted as red diamonds in Figure 2) is also shown. Black points represent the $\mathrm{h}(\mathrm{x})$ derived from $3 \mathrm{~min}$ DSD data in the outer bands of hurricane Irma that produced $8 \mathrm{~h}$ of rainfall at the HSV site. These are in reasonable agreement with data from the Dorian rainbands, although the composite $\mathrm{h}(\mathrm{x})$ lay slightly closer to Irma than Dorian data, especially for $\mathrm{x}>2$. A color-intensity plot 
of the Dorian-based $h(x)$ is shown in Figure $3 b$ with the composite $h(x)$ curve from HSV and GXY; once again, the agreement for $0.25<\mathrm{x}<2.0$ is very close.
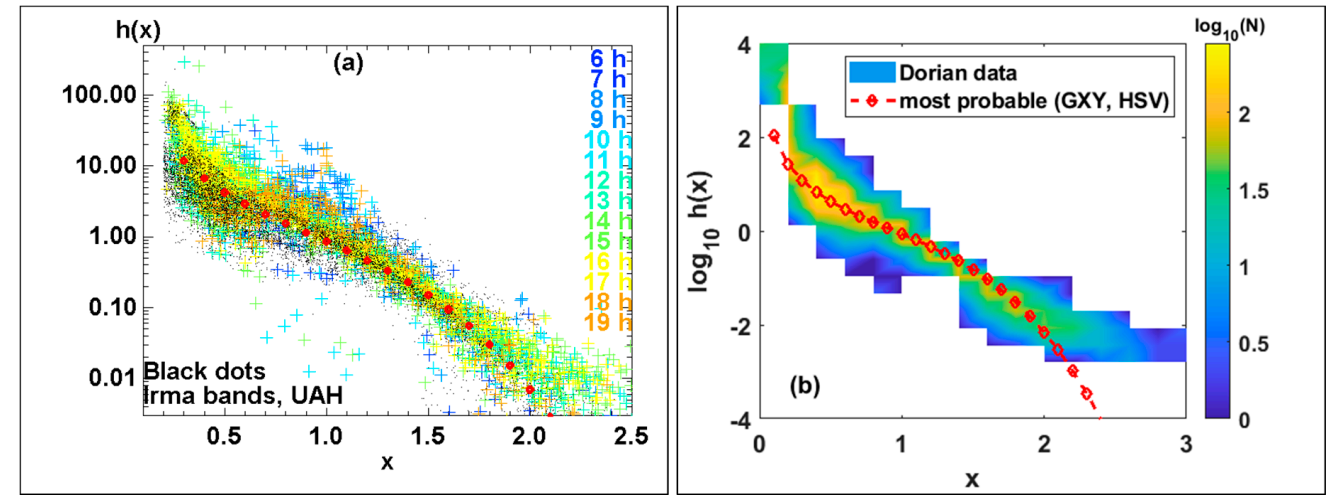

Figure 3. (a) $h(x)$ versus $x$ from 06:00 to 20:00 UTC. Each color represents each hour. Black points represent $\mathrm{h}(\mathrm{x})$ derived from $3 \mathrm{~min}$ DSD data in outer bands of hurricane Irma at HSV site. Red diamonds represent same most probable $\mathrm{h}(\mathrm{x})$ versus $\mathrm{x}$ from composite DSDs from GXY and HSV as in Figure 2. (b) Color intensity plot of $\mathrm{h}(\mathrm{x})$ for whole Dorian rainband event and most probable or composite $\mathrm{h}(\mathrm{x})$ curve from GXY and HSV data (same as red diamonds in Figure 3a).

To illustrate this more quantitatively, in Figure 4 we show the boxplot of the resulting bias (defined as $\Delta=$ Dorian - "reference") in drop concentration, N(D), expressed in terms of relative bias $(\Delta /$ mean ("reference")), if we assume the $\mathrm{h}(\mathrm{x})$ derived for the GXY and HSV data is the "truth". Recall that $\mathrm{N}(\mathrm{D})=\mathrm{N}_{0}{ }^{\prime} \mathrm{h}(\mathrm{x})$. The central mark is the median, edges represent the 25th and 75th percentiles, and outliers are plotted individually. Up to $4 \mathrm{~mm}$ drop diameters, the relative bias was less than $50 \%$, although the median values tended to be slightly positive ( $x$-axis scale is not uniform). Between 0.5 and $4 \mathrm{~mm}$, the use of the most probable $\mathrm{h}(\mathrm{x})$ from GXY and HSV especially resulted in very close representation of the Dorian DSDs. With the caveats mentioned earlier with reference to high gusting winds affecting concentrations for $\mathrm{D}<0.5 \mathrm{~mm}$, the use of the composite $\mathrm{h}(\mathrm{x})$ results in underestimation of Dorian drop concentrations by about 20-30\% (except for the smallest size considered here, which may have had relatively large measurement errors associated with them).

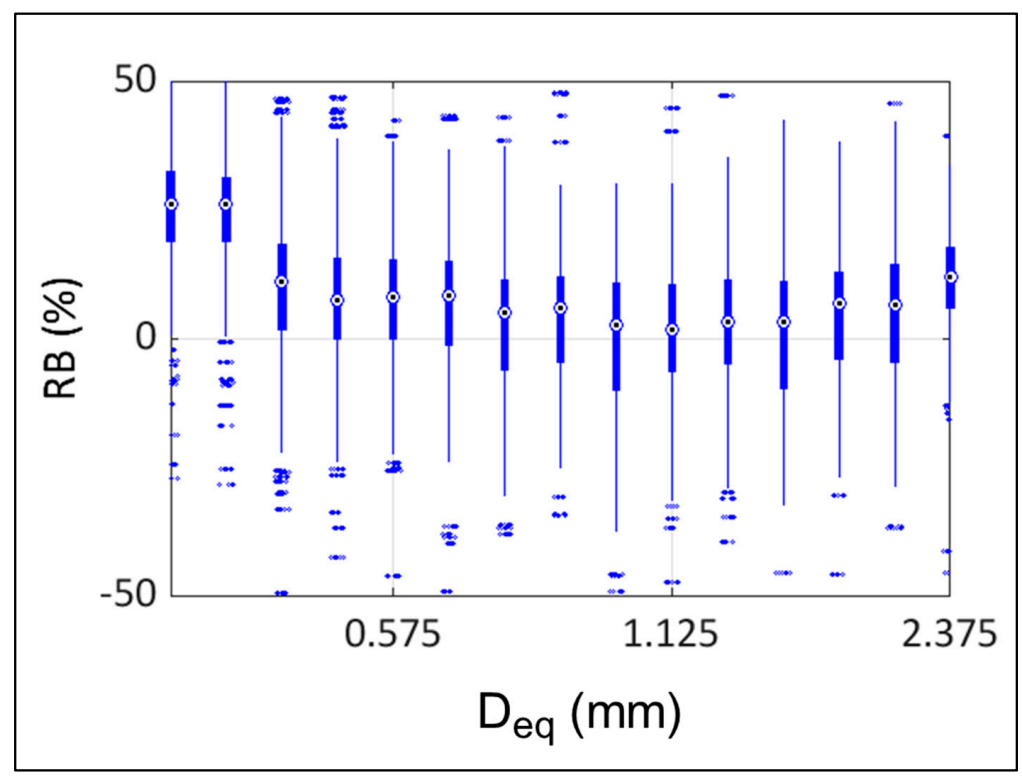

Figure 4. Relative bias in N(D) if we use the most probable $h(x)$ from GXY and HSV to reconstruct Dorian rainband DSDs. 


\subsection{Generalized Gamma Fits}

Now we examine whether the measured DSDs could be fitted to the generaligamma (GG) model $[17,21,33]$. This basically entails $\mathrm{h}(\mathrm{x})$ in Equation (1) to be expressed in terms of the two chosen reference moments with two shape parameters $\left(\mu_{\mathrm{GG}}, \mathrm{c}\right)$. Following the same notation as that of Lee et al. [17], $\mathrm{h}(\mathrm{x})$ is expressed as:

$$
h_{G G(i, j, \mu, c)}(x)=c \Gamma_{i}^{\frac{\left(j+c \mu_{G G}\right)}{(i-j)}} \Gamma_{j}^{\frac{\left(-i-c \mu_{G G}\right)}{(i-j)}} x^{c \mu_{G G}-1} \exp \left[-\left(\frac{\Gamma_{i}}{\Gamma_{j}}\right)^{\frac{c}{(i-j)}} x^{c}\right]
$$

with

$$
\Gamma_{\mathrm{i}}=\Gamma\left(\mu_{\mathrm{GG}}+\frac{\mathrm{i}}{\mathrm{c}}\right)
$$

and

$$
\begin{gathered}
\Gamma_{j}=\Gamma\left(\mu_{G G}+\frac{j}{c}\right) \\
i=3 ; j=4
\end{gathered}
$$

The optimal values of $\mu_{\mathrm{GG}}$ and c were obtained by minimizing the sum of squared difference between $\log _{10}\left(\mathrm{~h}_{\mathrm{GG}}\right)$ and the $\log _{10}$ of double-moment normalized composite $\mathrm{N}(\mathrm{D})$ using global search.

Four examples are shown in Figure 5, where $5 \mathrm{~min}$ DSDs were used for the fitting. The averaging over 5 min corresponded to a spatial scale of $1.2 \mathrm{~km}$ assuming the rainbands were advecting at $4 \mathrm{~m} / \mathrm{s}$. Figure $5 \mathrm{a}$,b shows the measured DSDs and the fitted curves for two time intervals during the main passage of the rainbands over the site. The fitted $\mu_{\mathrm{GG}}$ values were slightly negative $(-0.32$ and -0.38 , respectively) and values of $\mathrm{c}$ are 3.51 and 3.71 , respectively. These are somewhat similar to the composite combination of $\left(\mu_{\mathrm{GG}}=-0.25, \mathrm{c}=4\right)$ derived from the joint $\mathrm{GXY}$ and HSV data analyses. The slightly more negative $\mu_{\mathrm{GG}}$ values seen with Dorian DSD indicate, once again, the modest higher drop concentration of small drops. The standard gamma (SG) from [11] is equivalent to Equation (5) with $\mathrm{c}=1$ and $\mu_{\mathrm{GG}}=\mu_{\mathrm{SG}}-1$; given that our fitted $\mathrm{c}$ values were very different from 1 , the $\mathrm{SG}$ is clearly not sufficiently accurate to represent Dorian DSD measurements. Collocated micro-rain-radar (MRR) [34] observations for each of the four panels are included as an inset. The height along the $\mathrm{y}$-axis ranged from 0 to $1.25 \mathrm{~km}$, and the time along the $\mathrm{x}$-axis spanned $1 \mathrm{~h}$. Effective radar reflectivity $\mathrm{Z}_{\mathrm{e}}$ (K-band, $24 \mathrm{GHz}$ ) was fairly uniform with height in Figure $5 \mathrm{a}, \mathrm{b}$.

Figure $5 \mathrm{c}$ shows an example where even the GG model was unable to represent the measured DSDs with high fidelity. This occurred at 08:00 UTC just prior to the passage of the main rainbands. During this period, a small but noticeable plateau region in N(D) was observed for drop sizes in the range of 1-1.5 mm. It was not clear whether this was due to some discontinuity between MPS and 2DVD near $1 \mathrm{~mm}$ (recall that MPS concentrations were composited with the 2DVD at $1 \mathrm{~mm}$ ). However, MRR showed a rapid increase in reflectivity below $500 \mathrm{~m}$ down to ground level (increase from 20 to $40 \mathrm{dBZ}$ ) indicating low-level growth, presumably due to efficient coalescence process. In contrast, Figure $5 \mathrm{a}, \mathrm{b}$ shows much more uniform reflectivity-height variation during the main rainband passage, consistent with stratiform rain with a bright band.

Figure $5 \mathrm{~d}$ at 18:00 UTC corresponds to the near end of the rainbands over the disdrometer site. A decrease in drop concentration was seen below $1 \mathrm{~mm}$ drop diameter. A similar feature was observed during tropical depression Nate over HSV, again towards the end of the event (for an example, see Figure $7 \mathrm{~d}$ of [35]). One reason for this could be an intrusion of drier air behind the rainbands causing significant evaporation of small drops. The MRR plot shows the reflectivity profiles becoming shallower with time. The fitted GG curve closely represented the measured DSD, but the fitted $\mu$ value was significantly positive $(>2)$ reflecting the convex down shape at the small drop end, and the fitted $\mathrm{c}$-value was around 1.8, which was lower than the $\mathrm{c}=4$ derived for the GXY-HSV datasets. Hence, for such cases, one would not expect the composite underlying shape to accurately represent the DSDs. 

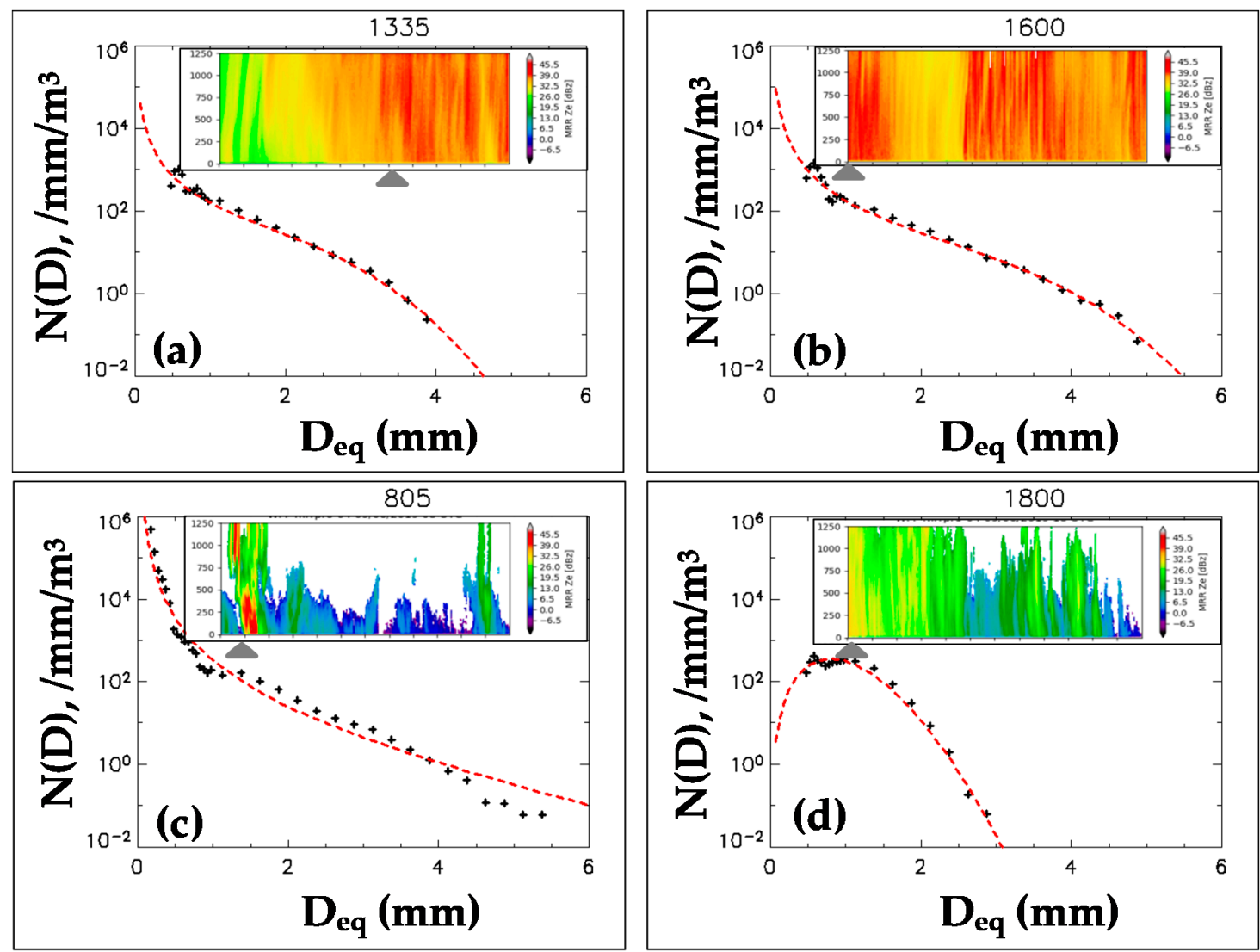

Figure 5. Four examples of $5 \mathrm{~min}$ DSDs (plus points) and their fitted generalized gamma (GG) curves (red dashed lines) for (a) 13:35-13:40, (b) 16:00-16:05, (c) 08:05-08:10, and (d) 18:00-18:05 UTC. Collocated micro-rain-radar (MRR) observations are included as an inset in each panel. Grey arrows represent the corresponding start times of the DSDs.

\section{NPOL Radar Observations}

Figure $6 \mathrm{a}, \mathrm{b}$ shows the $\mathrm{Z}_{\mathrm{h}}$ and $\mathrm{Z}_{\mathrm{dr}}$ from NPOL RHI scan taken along the azimuth of the disdrometer site at 15:41 UTC, which was around the time when $D_{m}$ from the ground-based DSDs reached a maximal value of almost $2.5 \mathrm{~mm}$. Figure $6 \mathrm{c}$ shows height variations above the disdrometer site (data averaged over a $1 \mathrm{~km}$ range interval centered at $38 \mathrm{~km}$ range). The range to the disdrometer site is marked by a vertical black dashed line. The bright-band (BB) was clearly visible at $4 \mathrm{~km}$ AGL in $\mathrm{Z}_{\mathrm{h}}$, but significantly less visible in $Z_{\mathrm{dr}}$ (i.e., smaller enhancement in the bright band relative to rain below). The Wallops sounding at 15:00 UTC showed that the height of the $0{ }^{\circ} \mathrm{C}$ was $4.4 \mathrm{~km}$, surface temperature was $22{ }^{\circ} \mathrm{C}$, and relative humidity was $94 \%$. A remarkable feature was the high value of peak $Z_{h}$ in the BB (nearly $55 \mathrm{dBZ}$ ) with around $11 \mathrm{~dB}$ fall off in the rain below. The vertical extent of the bright band (in $\mathrm{Z}_{\mathrm{h}}$ ) was quite deep, around $750 \mathrm{~m}$ over the disdrometer site. These values are unusual relative to the statistics derived in [36], although their study utilized an X-band radar. Drops as large as $5 \mathrm{~mm}$ were recorded by the 2DVD. Gatlin et al. [37] found that stratiform rain with a thick bright band (often associated with larger melting snow particles) tends to produce larger drops; even so, $5 \mathrm{~mm}$ drops are relatively rare in non-convective events.

The height variation of $Z_{\mathrm{dr}}$ was also remarkable, varying nearly linearly from $0 \mathrm{~dB}$ at $4 \mathrm{~km}$ AGL (top of melting layer) to $1.5 \mathrm{~dB}$ at $3 \mathrm{~km}$ (bottom of the melting layer) with no obvious peak in between. The dip in $\rho_{\mathrm{hv}}$ to 0.85 at $3.5 \mathrm{~km}$ AGL was also quite unusual at the S-band, but was observed by Illingworth and Caylor [38], who found the mode to be around 0.9. Zrnic et al. [39] found dips in $\rho_{\mathrm{hv}}$ to 0.82 in the stratiform region of a mesoscale convective system (MCS), and ascribed it to large wet snow of maximal sizes of around $12 \mathrm{~mm}$. Carlin and Ryzhkov [40] showed that, using a 1D bin-resolved 
melting model, bright-band thickness and maximal bright band $\mathrm{Z}$ (and, by inference, the $\rho_{\mathrm{hv}}$ dip) were all sensitive to the ambient environment (lapse rate and humidity at $0{ }^{\circ} \mathrm{C}$ ), while differential reflectivity $Z_{\mathrm{dr}}$ was relatively insensitive. Taken together $\left(\Delta Z_{\mathrm{h}}\right.$ of $12 \mathrm{~dB}$, the deep minima in $\rho_{\mathrm{hv}}$ and the absence of a distinct peak in $Z_{\mathrm{dr}}$ at the base of the $\mathrm{ML}$ relative to rain below), the simulations of [40] indicated that lapse rates could be $<-6.5^{\circ} / \mathrm{km}$ with relative humidity (RH) close to $100 \%$ at $0{ }^{\circ} \mathrm{C}$. From the sounding at 15:00 UTC at Wallops, lapse rate from surface to $3.5 \mathrm{~km}$ was $-5{ }^{\circ} \mathrm{C} / \mathrm{km}$ and $\mathrm{RH}$ at $0{ }^{\circ} \mathrm{C}$ was $98 \%$. Riming and aggregation, which is not unusual in the humid environment of hurricane rainbands, cannot be excluded. Below the $\mathrm{ML}$, the $\mathrm{Z}_{\mathrm{h}}$ decreased with decreasing height to the surface by $\approx 3 \mathrm{~dB}$, while $\mathrm{Z}_{\mathrm{dr}}$ also decreased from 1.5 to $1 \mathrm{~dB}$. The decreasing trend in both of these parameters indicates that break-up is the dominant process. Another noticeable feature from Figure 6, particularly Figure $6 \mathrm{~b}$, is the layer of high $\mathrm{Z}_{\mathrm{dr}}$ at height of $7.5 \mathrm{~km}$ above ground level $\left(-15^{\circ} \mathrm{C}\right)$. This is a well-documented feature that represents the so-called dendritic growth layer that often occurs at temperatures of -10 to $-15^{\circ} \mathrm{C}$ [41]. The peak in $Z_{\mathrm{dr}}$ at $7.5 \mathrm{~km}$ is also clearly visible in Figure $6 \mathrm{c}$ with a corresponding decrease in $\rho_{\mathrm{hv}}$. Below $7 \mathrm{~km}$, a rapid increase in $Z_{\mathrm{h}}$ is seen to occur (from $20 \mathrm{dBZ}$ at $6.5 \mathrm{~km}$ or $-10^{\circ} \mathrm{C}$ to $40 \mathrm{dBZ}$ at $4.5 \mathrm{~km}$ or $0^{\circ} \mathrm{C}$ ) or a staggering slope of $-10 \mathrm{~dB} / \mathrm{km}$, indicative of very strong aggregation process that was also reflected in the maximal $Z_{\mathrm{h}}$ of $55 \mathrm{dBZ}$ and $\Delta \mathrm{Z}_{\mathrm{h}}$ of $11 \mathrm{~dB}$.
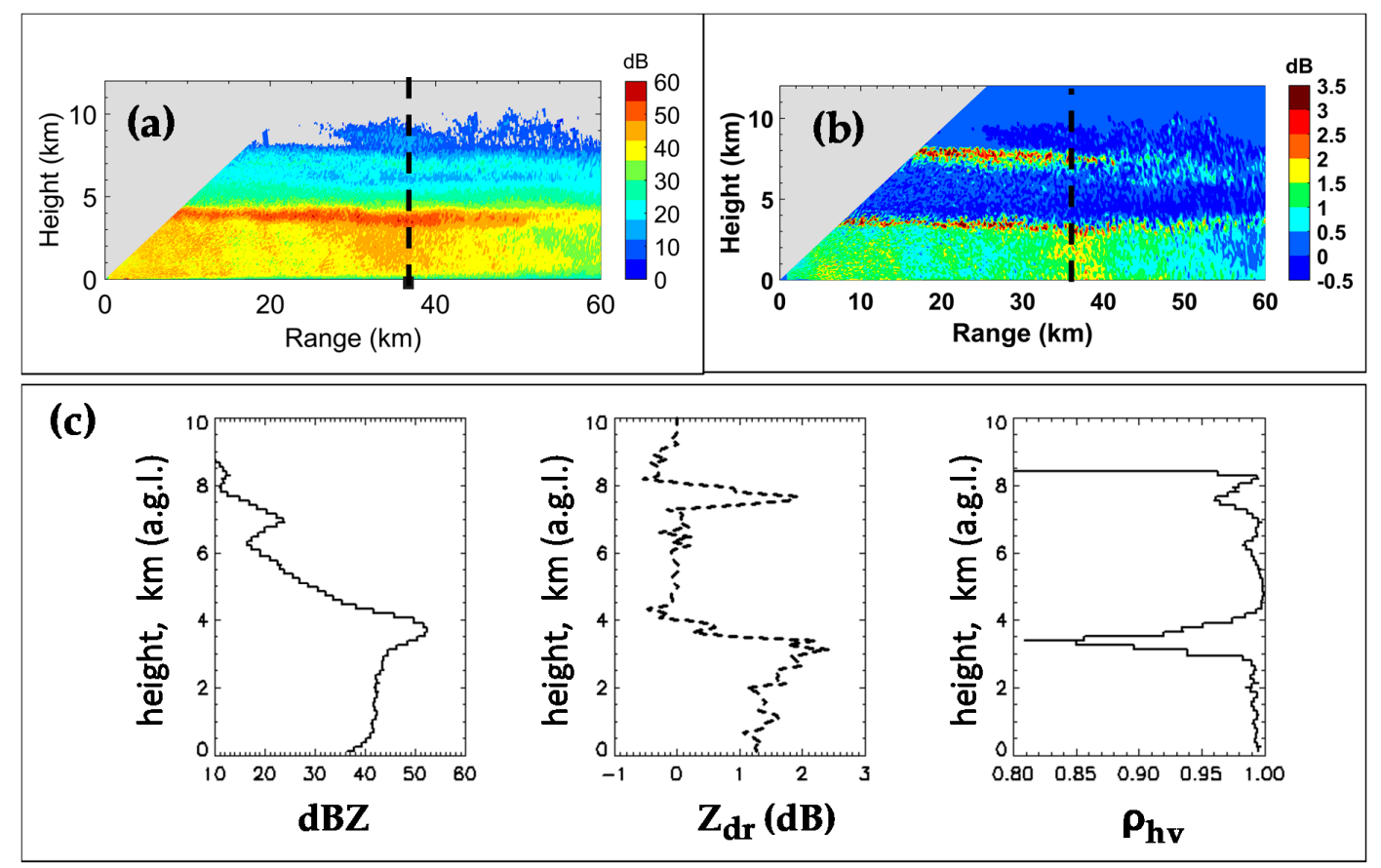

Figure 6. NPOL RHI scans of (a) dBZ and (b) $Z_{\mathrm{dr}}$ taken at 15:41 UTC on 6 September 2019 along disdrometer azimuth. Black dashed line shows range of disdrometer location. (c) Vertical profiles of $\mathrm{dBZ}, \mathrm{Z}_{\mathrm{dr}}$, and $\rho_{\mathrm{hv}}$ over disdrometer site.

\section{Radar Data and DSDs}

NPOL data from 08:20 to 21:00 UTC were processed to extract $Z_{\mathrm{h}}$ and $Z_{\mathrm{dr}}$ over the disdrometer site. From the vertical profiles of $Z_{h}$ and $Z_{d r}$, for example, Figure $6 c$, clutter effects were found to be significant up to approximately $300 \mathrm{~m}$ above ground level. Figure $7 \mathrm{a}$,b shows the extracted $Z_{\mathrm{h}}$ and $Z_{\mathrm{dr}}$ at heights ranging from 400 to $600 \mathrm{~m}$ above the disdrometer site, and over a range interval from 37 to $39 \mathrm{~km}$. The extracted data were from RHIs over the site, with repeat time of around 7 min shown in panels $\left(a: Z_{h}\right.$ and $b: Z_{d r}$ ). The $Z_{h}$ showed relatively smooth variation with time (a consequence of $d B$ scale with large dynamic range), whereas $Z_{\mathrm{dr}}$ showed high pixel-to-pixel fluctuations. Such 'noise' could be filtered out either by applying iterative FIR filtering along each range profile (similar to that applied for differential propagation phases [42]) or by applying the so-called "Lee filter" that 
is a standard technique to reduce speckle noise [43]. Both techniques were compared in our prior studies and shown to give consistent results (e.g., see Figure 2 in [44]). The red curve in Figure $7 \mathrm{~b}$ shows the Lee-filtered $Z_{\mathrm{dr}}$. Figure $7 \mathrm{c}$ shows this same variation (with time) with $\mathrm{D}_{\mathrm{m}}$ variation derived from ground-based DSD measurements. Excellent correlation can be seen with Pearson's correlation coefficient of 0.85 .

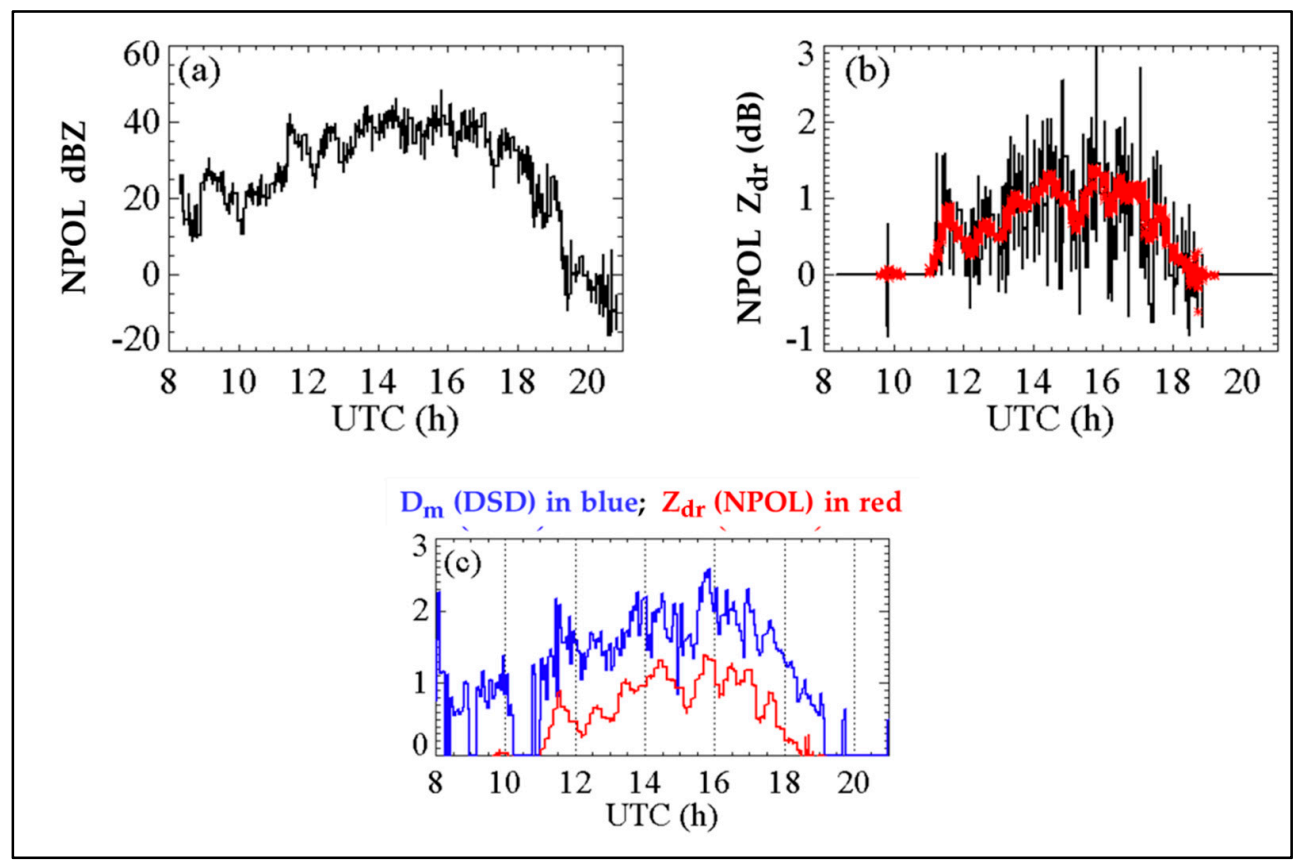

Figure 7. Extracted (a) $\mathrm{Z}_{\mathrm{h}}$ and (b) $\mathrm{Z}_{\mathrm{dr}}$ over and around disdrometer site from 400 to $600 \mathrm{~m}$ above sea level. Red line in (b) shows Lee-filtered Zdr. (c) Same red line as (b) and mass-weighted mean diameter (blue) from 3 min composite DSDs.

Figure 8a more clearly shows this variation. Values of $3 \mathrm{~min}$ DSD-based $\mathrm{D}_{\mathrm{m}}$ were extracted at the time of the NPOL RHI scans over the disdrometer. A clear variation of the NPOL $Z_{d r}$ with $D_{m}$ is seen, ranging from near zero $\mathrm{dB}$ for $\mathrm{D}_{\mathrm{m}}$ below $1 \mathrm{~mm}$, to $1.5 \mathrm{~dB}$ for $\mathrm{D}_{\mathrm{m}}$ as high as $2.5 \mathrm{~mm}$. A similar variation was also found with NPOL reflectivity, as shown in Figure 8b; here, we see an even clearer variation for $D_{\mathrm{m}}<1 \mathrm{~mm}$. For example, for $D_{\mathrm{m}}$ of around $0.5 \mathrm{~mm}$, NPOL data showed reflectivity of $\sim 11 \mathrm{dBZ}$ (range was 10-20 dBZ). This implies that, for light-rain rates (such as drizzle), $\mathrm{Z}_{\mathrm{h}}$ alone or combined with $Z_{d r}$ can be used to retrieve $D_{m}$.

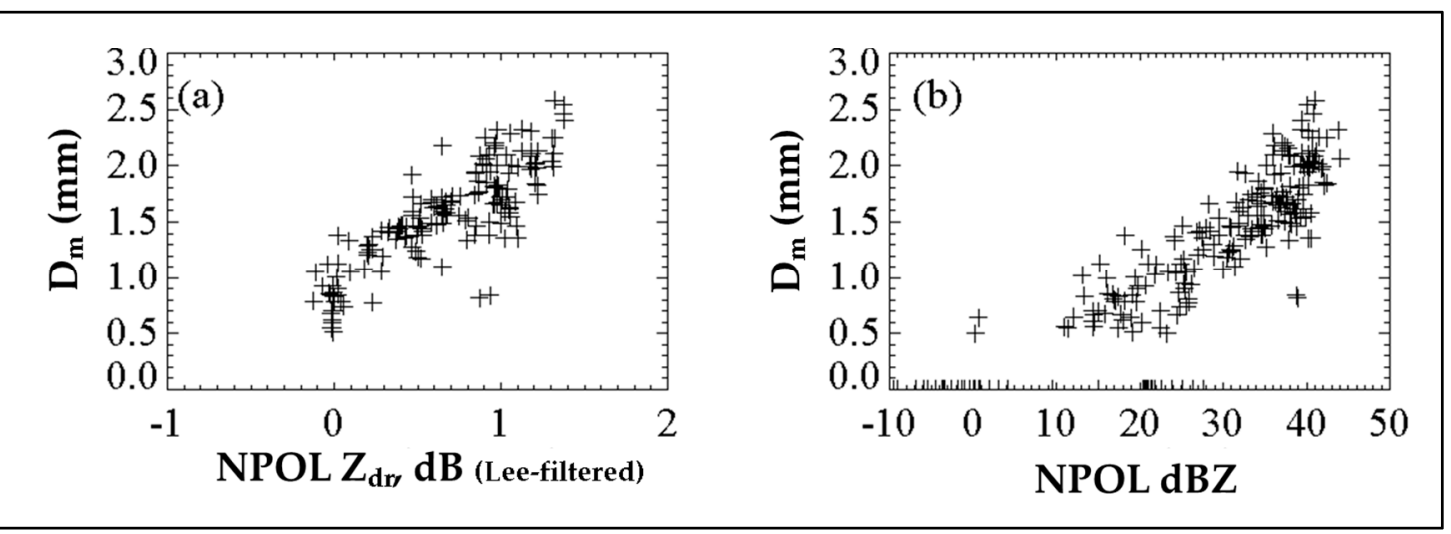

Figure 8. Mass-weighted mean diameter from 3 min DSDs versus (a) NPOL-based Lee-filtered $\mathrm{Z}_{\mathrm{dr}}$ and (b) NPOL-based $Z_{\mathrm{h}}$ over the disdrometer site. 


\section{Comparisons of DSD Characteristics}

The DSD datasets for Dorian's outer rainbands were obtained from a mid-latitude coastal location. We now compare the DSD characteristics with those from the outer bands of hurricane Irma (Category 1) as well as outer bands of tropical depression Nate, both over HSV, which is an inland subtropical location. Specifically, variations of $\mathrm{N}_{0}{ }^{\prime}$ versus $\mathrm{D}_{\mathrm{m}}^{\prime}$; were considered. These variations are compared in Figure 9. They all showed stratiform rain characteristics, similar to those found by Bringi et al. [45], which are a near-linear decrease of $\log _{10}\left(\mathrm{~N}_{0}{ }^{\prime}\right)$ with increasing $\mathrm{D}_{\mathrm{m}}^{\prime}$. The slope of variation was equivalent to what was found by Bringi et al. [45] for stratiform rain from tropical locations such as Florida to the high plains of Colorado. Their variations were given in terms of $N_{W}$ versus $D_{m}$. Using the relationship $\mathrm{N}_{\mathrm{W}}=\left(4^{4} / 6\right) \mathrm{N}_{0}{ }^{\prime}$, the gradients in all cases were very similar (almost [1:1] for $\log _{10}\left(\mathrm{~N}_{0}\right)$ versus $D_{m}$ ). However, Dorian rainbands generally showed higher $D_{m}$ than those of the two other cases because of the very large peak $Z_{h}$ in the $B B$, the large $\Delta Z_{h}$, and very strong aggregation inferred above the BB. In contrast, the outer rainbands of Nate showed weak and "thin" BB (peak $Z_{\mathrm{h}}$ of around 15-20 dBZ) and at times shallow rain (pure warm rain), while Irma had a peak $Z_{\mathrm{h}}$ of around $35-40 \mathrm{dBZ}$ with thickness of $<500 \mathrm{~m}$ (see, for example, [35]). The corresponding $\left(\mathrm{N}_{0}{ }^{\prime}, \mathrm{D}_{\mathrm{m}}^{\prime}\right)$ points generally fell in the tropical/subtropical segment of the stratiform rain line of Bringi et al. [45] that was also consistent with these rainbands being sampled at a subtropical location i.e., Huntsville, AL. In contrast, the rainbands of Dorian showed $\left(\mathrm{N}_{0}{ }^{\prime}, \mathrm{D}_{\mathrm{m}}^{\prime}\right)$ points tracking the stratiform rain line from the subtropical to the mid-latitudes.

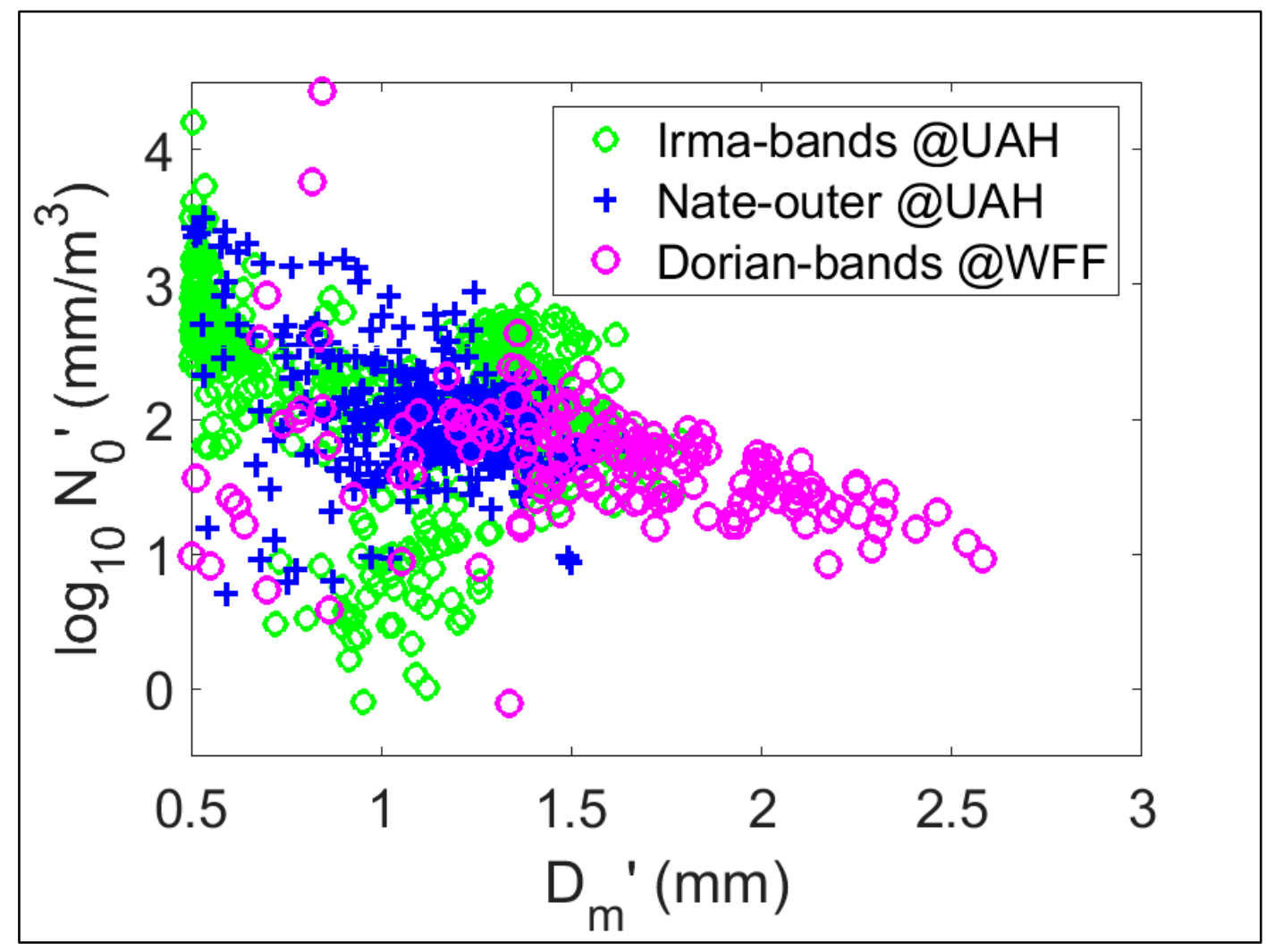

Figure 9. $\mathrm{N}_{0}{ }^{\prime}$ versus $\mathrm{D}_{\mathrm{m}}^{\prime}$ (same as $\mathrm{D}_{\mathrm{m}}$ ) from 3 min DSD for Dorian rainbands compared with those from the outer bands of hurricane Irma and from outer bands of tropical depression Nate, both at HSV.

\section{Conclusions}

A detailed description of the rainbands of Category 1 hurricane Dorian as it traversed across the Wallops precipitation research facility was provided from the perspective of the evolution of the DSD spectra and vertical profiles from NPOL radar RHI scan data. The intrinsic shape of the DSD 
after double-moment normalization using $\mathrm{M}_{3}$ and $\mathrm{M}_{4}$ as the reference moments, termed here as $\mathrm{h}(\mathrm{x})$, where $\mathrm{x}=\mathrm{D} / \mathrm{D}_{\mathrm{m}}^{\prime}$ showed that the 3 min DSD-based $\mathrm{h}(\mathrm{x})$ was close in shape to the composite $\mathrm{h}(\mathrm{x})$ based on over $40003 \mathrm{~min}$ DSDs from semi-arid Greeley, CO (GXY) and the subtropical Huntsville, AL (HSV) climates. Because of high gusting winds, the minimal D from the MPS was conservatively selected as $0.5 \mathrm{~mm}$, as opposed to $0.1 \mathrm{~mm}$ in prior studies. Nevertheless, the use of the MPS for $0.5 \leq \mathrm{D}<1 \mathrm{~mm}$ and the 2DVD for $\mathrm{D} \geq 1 \mathrm{~mm}$ gave a good indication of the shape at the small drop end. The $h(x)$ from the entire period of the Dorian rainbands was also compared with (i) the average $\mathrm{h}(\mathrm{x})$ from the outer rainbands of Irma ( $8 \mathrm{~h}$ of rainfall) and (ii) the most probable $\mathrm{h}(\mathrm{x})$ from GXY-HSV with very good agreement for $0.25 \leq x \leq 2$. The Dorian $h(x)$ was fitted to the generalized gamma (GG) distribution characterized by two shape parameters $\mu_{\mathrm{GG}}$ and c. At time resolution of $5 \mathrm{~min}$, the fitted GG $h(x)$ was un-normalized to obtain a fitted N(D) that was then compared with "raw" DSDs. The fidelity of the GG fit was excellent during the main rainband passage over the site, except at the very beginning and tail end, when the vertical profiles of $Z_{h}$ from the MRR showed no bright band, but more convective features. The beginning time was characterized by low-level growth (coalescence) producing large drops ( $\max \mathrm{D} \approx 4$ to $5 \mathrm{~mm}$ ) whereas the tail-end-fitted $\mathrm{N}(\mathrm{D})$ showed a convex down shape for $\mathrm{D}<0.5 \mathrm{~mm}$, characteristic of evaporation. During the main rainband passage, the fitted $\mathrm{N}(\mathrm{D})$ was excellent, showing the concave up shape at the small drop end, and steeper (than exponential) fall off at the large drop end ( $\max \mathrm{D} \approx 5 \mathrm{~mm}$ ).

The most remarkable features were the height profiles from NPOL RHI scans over the site. The peak $\mathrm{Z}_{\mathrm{h}}$ in the melting layer (ML) (bright band or BB peak) was, at times, near $55 \mathrm{dBZ}$, with $\Delta \mathrm{Z}_{\mathrm{h}} \approx 11 \mathrm{~dB}$ (difference between BB peak and the rain below). The $\rho_{\mathrm{hv}}$ dipped to 0.85 in the ML, which was unusual at the S-band and could have only occurred if the backscatter differential phase ( $\delta$ defined in [13]) varied across the ML, which was indeed the case (not shown here). Zrnic et al. [39] also measured a similar dip in $\rho_{\mathrm{hv}}$ in the ML of the stratiform region of a mesoscale convective system (MCS), and ascribed it to a variation of $\delta$ across the ML caused by large $12-15 \mathrm{~mm}$ wet snow. The $Z_{\mathrm{dr}}$ profile showed a weak or nonexistent $B B$ peak, but the $Z_{d r}$ increased very rapidly, from near $0 \mathrm{~dB}$ at the top of the ML to $1.5 \mathrm{~dB}$ within $500 \mathrm{~m}$. The large wet snow melted to form large raindrops, with $\mathrm{D}_{\mathrm{m}}$ peaks of $2.5 \mathrm{~mm}$. However, the $\mathrm{N}_{\mathrm{w}}$ was a factor of 6 lower than the Marshall-Palmer $\mathrm{N}_{0}$ of $8000 \mathrm{~mm}^{-1} \mathrm{~m}^{-3}$ leading to low rain rates of $<12 \mathrm{~mm} / \mathrm{h}$. The height profile of $Z_{\mathrm{h}}$ and $Z_{\mathrm{dr}}$ below the ML to the surface indicated break-up as the dominant process (with both $\delta Z_{h}$ and $\delta Z_{d r}$ being negative [46]).

Above the $M L$, the positive $Z_{\mathrm{dr}}$ signature indicating the dendritic growth layer at $7.5 \mathrm{~km}$ AGL $\left(T=-15^{\circ} \mathrm{C}\right)$ was observed similar to numerous studies ([14,36] and references therein). The slope of $\mathrm{Z}_{\mathrm{h}}$ from 6.5 to $4.5 \mathrm{~km}$ was a remarkable $-10 \mathrm{~dB} / \mathrm{km}$, indicating aggregation as the dominant growth process. Together with peak $B B Z_{h}$ of $55 \mathrm{dBZ}$, the Dorian rainbands were indeed unique.

The NPOL-observed $Z_{h}$ and $Z_{d r}$ extracted over the site were compared with $D_{m}$ from the measured DSDs both as time series and as scatterplots. The main finding was that $\mathrm{D}_{\mathrm{m}}$ could potentially be retrieved using both $Z_{h}$ and $Z_{d r}$ when $D_{m}$ is small $(<1 \mathrm{~mm})$, and perhaps using only $Z_{h}$ for smaller $D_{m}$ (very light rain rates). Finally, the $N_{0}{ }^{\prime}$ versus $D_{m}$ plot showed that Dorian rainbands followed the stratiform rain line slope from Bringi et al. [45]. As rainbands traversed the site, the $\mathrm{N}_{0}{ }^{\prime}$ and $\mathrm{D}_{\mathrm{m}}^{\prime}$ pairs followed the stratiform rain line exhibiting subtropical to midlatitude continental characteristics, unlike the rainbands of tropical depression Nate or the outer bands of Irma over the Huntsville site that were characterized by subtropical stratiform $\left(\mathrm{N}_{0}{ }^{\prime}, \mathrm{D}_{\mathrm{m}}\right)$ pairs. Detailed analysis of the microphysics of (Category 1) Dorian rainbands demonstrated the value of using collocated MPS and 2DVD for DSD measurements along with polarimetric radar RHI scan data, which should serve as a test bed for validating microphysical process parameterizations such as break-up and aggregation.

Author Contributions: Conceptualization, M.T. and V.N.B.; methodology, investigation, and formal analysis, M.T. and V.N.B.; data curation, D.A.M. and D.B.W.; assistance, C.S.P.; writing-original-draft preparation, M.T.; writing-review and editing, V.N.B., D.B.W., and D.A.M.; supervision, V.N.B.; resources, D.B.W. All authors have read and agreed to the published version of the manuscript. 
Funding: M.T. received funding to conduct this research from NASA's Precipitation Measurement Mission via grant award number 80NSSC19K0676. V.N.B. was funded by the U.S. National Science Foundation under grant AGS190585.

Acknowledgments: We would like to thank Michael Hinton, Brandon Jameson, and several other staff members based at the Wallops Flight Facility for setting up the Meteorological Particle Spectrometer and for enabling data access.

Conflicts of Interest: The authors declare no conflict of interest. The funders had no role in the design of this study; in the collection, analyses, or interpretation of its data; in the writing of this manuscript, and in the decision to publish these results.

\section{References}

1. Wolff, D.B.; Marks, D.A.; Petersen, W.A. 2015: General Application of the Relative Calibration Adjustment (RCA) Technique for Monitoring and Correcting Radar Reflectivity Calibration. J. Atmos. Ocean. Technol. 2015, 32, 496-506. [CrossRef]

2. Merceret, F.J. On the Size Distribution of Raindrops in Hurricane Ginger. Mon. Wea. Rev. 1974, 102, 714-716. [CrossRef]

3. Jorgensen, D.P.; Willis, P.T. A Z-R relationship for hurricanes. J. Appl. Meteorol. 1982, 21, 356-366. [CrossRef]

4. McFarquhar, G.M.; Black, R.A. Observations of particle size and phase in tropical cyclones: Implications for mesoscale modeling of microphysical processes. J. Atmos. Sci. 2004, 61, 422-439. [CrossRef]

5. Tokay, A.; Bashor, P.G.; Habib, E.; Kasparis, T. Raindrop Size Distribution Measurements in Tropical Cyclones. Mon. Wea. Rev. 2008, 136, 1669-1685. [CrossRef]

6. Feng, Y.-C.; Bell, M.M. Microphysical Characteristics of an Asymmetric Eyewall in Major Hurricane Harvey. Geophys. Res. Lett. 2017, 46, 461-471. [CrossRef]

7. Didlake, A.C.; Kumjian, M.R. Examining Polarimetric Radar Observations of Bulk Microphysical Structures and Their Relation to Vortex Kinematics in Hurricane Arthur (2014). Mon. Wea. Rev. 2017, 145, 4521-4541. [CrossRef]

8. Brown, B.R.; Bell, M.M.; Frambach, A.J. Validation of simulated hurricane drop size distributions using polarimetric radar. Geophys. Res. Lett. 2016, 43, 910-917. [CrossRef]

9. Wolff, D.B.; Petersen, W.A.; Tokay, A.; Marks, D.A.; Pippitt, J.L. Assessing Dual-Polarization Radar Estimates of Extreme Rainfall during Hurricane Harvey. J. Atmos. Ocean. Technol. 2019, 36, 2501-2520. [CrossRef]

10. Marshall, J.S.; Palmer, W.M.K. The distribution of raindrops with size. J. Meteorol. 1948, 5, 165-166. [CrossRef]

11. Ulbrich, C.W. Natural Variations in the Analytical Form of the Raindrop Size Distribution. J. Clim. Appl. Meteorol. 1983, 22, 1764-1775. [CrossRef]

12. Williams, C.R.; Bringi, V.N.; Carey, L.D.; Chandrasekar, V.; Gatlin, P.N.; Haddad, Z.S.; Meneghini, R.; Munchak, S.J.; Nesbitt, S.W.; Petersen, W.A. Describing the Shape of Raindrop Size Distributions Using Uncorrelated Raindrop Mass Spectrum Parameters. J. Appl. Meteorol. Climatol. 2014, 53, 1282-1296. [CrossRef]

13. Bringi, V.N.; Chandrasekar, V. Polarimetric Doppler Weather Radar: Principles and Applications; Cambridge University Press: Cambridge, UK, 2001.

14. Ryzhkov, A.; Zrnic, D.S. Radar Polarimetry for Weather Observations; Springer: Chaim, Switzerland, 2019.

15. Sempere-Torres, D.; Porrà, J.M.; Creutin, J.-D. Experimental evidence of a general description for raindrop size distribution properties. J. Geophys. Res. 1998, 103, 1785-1797. [CrossRef]

16. Testud, J.; Oury, S.; Black, R.A.; Amayenc, P.; Dou, X. The concept of "normalized" distribution to describe raindrop spectra: A tool for cloud physics and cloud remote sensing. J. Appl. Meteorol. 2001, 40, 1118-1140. [CrossRef]

17. Lee, G.; Zawadzki, I.; Szyrmer, W.; Sempere-Torres, D.; Uijlenhoet, R. A General Approach to Double-Moment Normalization of Drop Size Distributions. J. Appl. Meteorol. 2004, 43, 264-281. [CrossRef]

18. Yu, N.; Delrieu, G.; Boudevillain, B.; Hazenberg, P.; Uijlenhoet, R. Unified Formulation of Single- and Multimoment Normalizations of the Raindrop Size Distribution Based on the Gamma Probability Density Function. J. Appl. Meteorol. Climatol. 2014, 53, 166-179. [CrossRef]

19. Auf der Maur, A.N. Statistical tools for drop size distribution: Moments and generalized gamma. J. Atmos. Sci. 2001, 58, 407-418. [CrossRef] 
20. Petty, G.W.; Huang, W. The modified gamma size distribution applied to inhomogeneous and non-spherical particles: Key relationships and conversions. J. Atmos. Sci. 2011, 68, 1460-1473. [CrossRef]

21. Raupach, T.H.; Berne, A. Retrieval of the raindrop size distribution from polarimetric radar data using double-moment normalization. Atmos. Meas. Tech. 2017, 10, 2573-2594. [CrossRef]

22. Skofronick-Jackson, G.; Petersen, W.A.; Berg, W.; Kidd, C.; Stocker, E.F.; Kirschbaum, D.B.; Kakar, R.; Braun, S.A.; Huffman, G.J.; Iguchi, T.; et al. The Global Precipitation Measurement (GPM) Mission for science and society. Bull. Am. Meteorol. Soc. 2016, 98, 1679-1696. [CrossRef]

23. Knollenberg, R. The optical array: An alternative to scattering or extinction for airborne particle size determination. J. Appl. Meteorol. 1970, 9, 86-103. [CrossRef]

24. Baumgardner, D.; Kok, G.; Dawson, W.; O'Connor, D.; Newton, R. A new ground-based precipitation spectrometer: The Meteorological Particle Sensor (MPS). In Proceedings of the 11th Conference on Cloud Physics, Ogden, UT, USA, 3-7 June 2002. paper 8.6.

25. Bringi, V.N.; Thurai, M.; Baumgardner, D. Raindrop fall velocities from an optical array probe and 2-D video disdrometer. Atmos. Meas. Tech. 2018, 11, 1377-1384. [CrossRef]

26. Schoenhuber, M.; Lammer, G.; Randeu, W.L. One decade of imaging precipitation measurement by 2D-video-distrometer. Adv. Geosci. 2007, 10, 85-90. [CrossRef]

27. Schönhuber, M.; Lammer, G.; Randeu, W.L. The 2D-Video-Distrometer. In Precipitation: Advances in Measurement, Estimation and Prediction; Michaelides, S., Ed.; Springer: Berlin/Heidelberg, Germany, 2008; pp. 3-31. ISBN 978-3-540-77654-3.

28. OTT Hydromet GmbH. Operating Instructions: OTT Pluvio2 Precipitation Gauge; OTT Hydromet: Loveland, CO, USA, 2010; p. 60. Available online: http://www.ott.com/en-us/products/download/operatinginstructions-precipitation-gauge-ott-pluvio2/ (accessed on 14 April 2015).

29. Rasmussen, R.; Baker, B.; Kochendorfer, J.; Meyers, T.; Landolt, S.; Fischer, A.P.; Black, J.; Thériault, J.M.; Kucera, P.; Gochis, D.; et al. How Well Are We Measuring Snow: The NOAA/FAA/NCAR Winter Precipitation Test Bed. Bull. Am. Meteorol. Soc. 2012, 93, 811-829. [CrossRef]

30. Thurai, M.; Bringi, V.; Gatlin, P.N.; Petersen, W.A.; Wingo, M.T. Measurements and Modeling of the Full Rain Drop Size Distribution. Atmosphere 2019, 10, 39. [CrossRef]

31. Raupach, T.H.; Thurai, M.; Bringi, V.N.; Berne, A. Reconstructing the Drizzle Mode of the Raindrop Size Distribution Using Double-Moment Normalization. J. Appl. Meteorol. 2019, 58, 145-164. [CrossRef]

32. Illingworth, A.J.; Blackman, T.M. The Need to Represent Raindrop Size Spectra as Normalized Gamma Distributions for the Interpretation of Polarization Radar Observations. J. Appl. Meteorol. 2002, 41, $286-297$. [CrossRef]

33. Thurai, M.; Bringi, V.N. Application of the Generalized Gamma Model to Represent the Full Rain Drop Size Distribution Spectra. J. Appl. Meteorol. Climatol. 2018, 57, 1197-1210. [CrossRef]

34. Peters, G.; Fischer, B.; Münster, H.; Clemens, M.; Wagner, A. Profiles of Raindrop Size Distributions as Retrieved by Microrain Radars. J. Appl. Meteorol. 2005, 44, 1930-1949. [CrossRef]

35. Thurai, M.; Bringi, V.N.; Gatlin, P.N.; Petersen, W.A.; Wingo, M. Why the Generalized Gamma?-An Answer Based on Measurements with Meteorological Particle Spectrometer and 2D Video Disdrometer. In Proceedings of the 10th European Conference on Radar in Meteorology and Hydrology (ERAD 2018) 2018, Extended Abstract, 051, Wageningen, The Netherlands, 1-6 July 2018.

36. Trömel, S.; Ryzhkov, A.V.; Hickman, B.; Mühlbauer, K.; Simmer, C. Polarimetric Radar Variables in the Layers of Melting and Dendritic Growth at X Band-Implications for a Nowcasting Strategy in Stratiform Rain. J. Appl. Meteorol. Climatol. 2019, 58, 2497-2522. [CrossRef]

37. Gatlin, P.N.; Petersen, W.A.; Knupp, K.R.; Carey, L.D. Observed Response of the Raindrop Size Distribution to Changes in the Melting Layer. Atmosphere 2018, 9, 319. [CrossRef]

38. Illingworth, A.J.; Caylor, I.J. Polarization Radar Estimates of Raindrop Size Spectra and Rainfall Rates. J. Atmos. Ocean. Technol. 1989, 6, 939-949. [CrossRef]

39. Zrnić, D.S.; Raghavan, R.; Chandrasekar, V. Observations of Copolar Correlation Coefficient through a Bright Band at Vertical Incidence. J. Appl. Meteorol. 1994, 33, 45-52. [CrossRef]

40. Carlin, J.T.; Ryzhkov, A.V. Estimation of Melting-Layer Cooling Rate from Dual-Polarization Radar: Spectral Bin Model Simulations. J. Appl. Meteorol. Climatol. 2019, 58, 1485-1508. [CrossRef]

41. Kennedy, P.C.; Rutledge, S.A. S-Band Dual-Polarization Radar Observations of Winter Storms. J. Appl. Meteorol. Climatol. 2011, 50, 844-858. [CrossRef] 
42. Hubbert, J.; Bringi, V.N. An Iterative Filtering Technique for the Analysis of Copolar Differential Phase and Dual-Frequency Radar Measurements. J. Atmos. Ocean. Technol. 1995, 12, 643-648. [CrossRef]

43. Lee, J.S. Digital image enhancement and noise filtering by use of local statistics. IEEE Trans. Pattern Anal. Mach. Intell. 1980, 2, 165-168. [CrossRef]

44. Thurai, M.; Bringi, V.N.; Carey, L.D.; Gatlin, P.; Schultz, E.; Petersen, W.A. Estimating the Accuracy of Polarimetric Radar-Based Retrievals of Drop Size Distribution Parameters and Rain Rate: An Application of Error Variance Separation Using Radar-Derived Spatial Correlations. J. Hydrometeorol. 2012, 13, 1066-1079. [CrossRef]

45. Bringi, V.N.; Chandrasekar, V.; Hubbert, J.; Gorgucci, E.; Randeu, W.L.; Schoenhuber, M. Raindrop Size Distribution in Different Climatic Regimes from Disdrometer and Dual-Polarized Radar Analysis. J. Atmos. Sci. 2003, 60, 354-365. [CrossRef]

46. Kumjian, M.R.; Prat, O.P. The Impact of Raindrop Collisional Processes on the Polarimetric Radar Variables. J. Atmos. Sci. 2014, 71, 3052-3067. [CrossRef]

(C) 2020 by the authors. Licensee MDPI, Basel, Switzerland. This article is an open access article distributed under the terms and conditions of the Creative Commons Attribution (CC BY) license (http://creativecommons.org/licenses/by/4.0/). 